\title{
The Theme of Heart of Darkness from the Perspective of Ekphrasis
}

\author{
Fan Chen ${ }^{1, *}$
}

\author{
${ }^{1}$ Sichuan University, Chengdu, Sichuan 650021, China \\ *Corresponding author.Email:89647929@qq.com
}

\begin{abstract}
Heart of Darkness is a great novel composed of pictures by words to construct space and scenes. Because words and their meanings are not strictly corresponding or homologous, ekphrasis of visional representation is a surpassing remedy. By using description, juxtaposition, paste-up, and extension, Conrad's creation of the geographical landscapes of the Thames and the Congo has a more metaphorical expression than words. In readers' eyes, the tension between the exquisite and fracture forms a visual allegory - the appropriate representation of darkness in a theme of death, is break and fragmentation, other than coherence and uniformity.
\end{abstract}

Keywords: Ekphrasis, Visual allegory, Heart of Darkness.

\section{INTRODUCTION}

The previous discussions on Conrad's Heart of Darkness pointed out that the novel is logocentrism centered on "sound" ontologically and epistemologically. Sound is the foundation on which the novel constructed and the way by which readers multidimensional interpret. For example, Perry Meisel pointed out the novel's foundation on "sound" represented the hollowness and the boredom of the trip to Africa.[1] Vincent Pecora argued the "sounds" in novel, such as the sound of fracture, sound of nature, and the meaningless noises etc., representing the anti-imperialism.[2] However, looking further on, we could find the sound is always appears in the pictures. In other words, sound and picture are undividable. The novel has depicted a lot of scenes and sites. The author is actually constructing the soundimagination in pictures. Therefore, to analyze the ekphrasis of the novel is an urgent cultural task.

Ekphrasis is a rhetorical term dates back to the ancient Greek referring to the picture depicting by words, or using language to describe the visual phenomenon. The pictorial narration is a tradition in western history of novel theory. The first western novel theory, Lubbock's the Craft of Fiction (1921) has plenty of space to illustrate that novels are alternative visionary productions between pictures and scenes. [3] In the eight chapter of Aspects of
Novel (1927), E.M. Forster argued the relations between pictorial narration and the novel's beauty is inseparable and delicate. [4] All these proved the ekphrasis is a tradition in western novel written as well as in novel theory. Today the ekphrasis is not just a simple reproduction, or copying of pictures by words, but a complicated interaction among vision, discourse, power and rhetoric. As the picture description takes mostly length of the novel, we should ask what stimulate Conrad to construct the context on ekphrasis? Once ekphrasis becomes a creative writing method, how does meaning come into being in the visual world? In what way Heart of Darkness represented in its theme?

\section{THE NON-NARRATABILITY OF LANGUAGE AND THE HOPE OF EKPHRASIS}

The reason why the author makes the whole story on a pictorial narration is because the nonnarratability of language, in other words, for many reasons we cannot express the meaning by words directly or straightforward. We can have an insight of it in the beginning of the novel: "the meaning of an episode was not inside like a kernel but outside, enveloping the tale which brought it out only as a glow brings out a haze, in the likeness of one of these misty halos that sometimes are made visible by the spectral illumination of moonshine." [4] Conrad uses this vivid picture to illustrate that the 
images which cannot say directly by words can be approached by the pictorial narration, or, ekphrasis. Because words and its meaning are not strictly corresponding or homologous, ekphrasis of visional representation is a surpassing remedy. By composing pictures of "objective correlative" [5], the novel obtained the strength of reappearances of atmosphere. Therefore, the first aim of ekphrasis is realness, vividness and presence, to attract the readers as if they can see.

The "non-narratability" of language also manifested in the value judgement. While the language always has a value judgement when speaking and writing, for some reason or others, the unspeakable judgement should be kept silent with a form of picture instead of telling it forth by words. So, the second aim of ekphrasis is: the power metaphor of pictures. In other words, pictures take over many responsibilities by words that unspoken.

The most typical expression of pictures is the maps. Malow refers to the importance of a map in the beginning of his telling, "when I was a little chap, I had a passion for maps. I would look for hours at South America, or Africa, or Australia, and lose myself in all the glories of exploration. At that time there were many blank spaces on the earth, and when I saw one that looked particularly inviting on a map I would put my finger on it and say, when I grow up I will go there." [5] As imitating the geographical shapes, maps are not fully equate the terrain, but only a reflection and imagination of the physical world. So do all the scientific theories, which are not true world itself, but are imitative narrations. Hence, knowledge is constructive. Why the two rivers in the novel - the Congo, awesome, terrifying, and darkness; while the Tames, majestic, peaceful, and continuous in service of human - have bring about these opposite psychological maps? As knowledge and tools, maps would never tell what happened on the river. It reveals what we can know and hides what we could not see. And the power of maps relays in its hiding, rather than in its revealing. So, the real darkness is that all the knowledge would not tell you, and you could never know you would step into darkness. Therefore, as the last deceit of Malow, what the literal maps had deceived and for what reasons, we could never know. And the power metaphor lies here.

The third aim of ekphrasis is the moral inquiry accompanied with the darkness portraying. Narration by language always has timeliness and historicity, while the picture takes the space shape.
Using language to portray pictures would make space fluid and speaking in space shape. The past tense used in the novel coincidences with the picture's features: all the pictures are about the past things, expressing a moment in a past time and so with an atmosphere of mournful and threnetical, which is mourning for death and things that no longer exists, the moral inquiry arises here. Heart of Darkness is actually a metaphor about.

Ekphrasis in The Heart of Darkness yields metaphors than words: the importance of pictures and scenes lies in its relativities: how the physical environment produces a human society and human psychology. Therefore, Conrad's ekphrasis narrative is linking the core idea of home, power and modernity, using depicting, juxtaposition, and extension of pictures to create an artistic effect of vividly transmitting some ideas and values which cannot be spoken directly.

\section{THE DEPICTING, JUXTAPOSITION, AND EXTENSION OF THE DARKNESS}

At the beginning of the novel, Conrad uses the literary language to depict the sea-reach of the Thames river, stretching as a film frame. "The seareach of the Thames stretched before us like the beginning of an interminable waterway. In the offing the sea and the sky were welded together without a joint, and in the luminous space the tanned sails of the barges drifting up with the tide seemed to stand still in red clusters of canvas sharply peaked, with gleams of vanished spirit." [4] The long sentences depict the details and have a slow pace and a continuity sense as a long-shot of film to drive our attention from far to near and at last to focus on a man, which create a sense of loneliness. The pictures depicting in the opening are heavy and solemn, without any comments, readers would experience the feeling from this picture.

In contract with the Thames, Congo River is depicted as mystical, gruesome and monstrous. "all along the formless coast bordered by dangerous surf, as if Nature herself had tried to ward off intruders; in and out of rivers, streams of death in life, whose banks were rotting into mud, whose waters, thickened into slime invaded the contorted mangrover, that seemed to writhe at us in the extremity of an impotent despair." [4] The dangerous and horrible atmosphere were created by the recurrently appeared images — river, sky, clouds, groves, etc. - to form a pictorial 
representation system, from which a collage of dark pictures are engendered in an increased number. And these images are also be seen as a machine producing the dark pictures to form a chain of signifiers which intend to arouse the signified in readers' minds' eyes. The differences between signifier and signified proved the true meaning is always unavailable to the readers. Conrad is not telling a story revealing an affirmative truth. And as he told in Malow's words, the truth in not within the story, but outside it. And this is the mode of his story telling, to trigger readers' pictorial imagination about what is truth in what he is not tell.

The aim of the space description is to build readers' space experiences and feelings. Conrad is expert in describing the wild and wide spaces. Congo River stretches across vast area covering the hot, chaotic, and monstrous zones which would naturally arouse the reader's imagination on the distant places. "As we have plenty of wood, and caution was the word, I brought up in the middle of the stream. The reach was narrow, straight, with high sides like a railway cutting. The dusk came gliding into it long before the sun had set. The current ran smooth and swift, but a dumb immobility sat on the banks. The living trees, lashed together by the creepers and every living bush of the undergrowth, might have been changed into stone, even to the slenderest twig, to the lightest leaf." [4] The pictures of Africa is full of light, colors and the fluctuating of lights and colors in which the sense of time and space was built. Readers are experiencing in this horrible scene, and was frightened by it, and arising a thinking on the eternal human nature.

Space depiction, pictures juxtaposition and extension are the way this novel spreading. At the end of the novel, "the offing was barred by a black bank of clouds, and the tranquil waterway leading to the uttermost ends of the earth flowed somber under an over cast sky - seemed to lead into the heart of an immense darkness". [4] The ending picture of the Congo is echoed with the beginning picture of the novel. The fluid river takes us to the heart of an immense darkness. The visual representation of pictures and scenes is eliminating the stereotyped preaching by words and has a great artistic effect.

\section{THE VISIONAL ALLEGORY OF DARKNESS}

The representation of pictures is not equal to the perception of pictures. So, the other side of ekphrasis is how we describe our feelings as readers, or how the darkness represented by readers' vision.

Malow as a story teller presents in 4 novels of Conrad. Malow's elaborately story is actually told by the real narrator of the novel. The aim and meaning of this double layer of narration is to prove that watching is an interaction of multi-angle and the subject as well as the object are constructive from each other's eye.

In this process of interactive watching, the author tries to lead the reader have an allegory watching modes - the essence is anti-essence. The etymology of the word allegory - allos (other) and ag-oreuein (speak) — proved the allegory etymologically is the other speak, translucent, not opaque. From Romanticism, allegory is stepping from a kind of expression to a generating mechanism. The heterogeneous components inside of it formed an antimony. In the continuous dismantling, the readers uncover, dissemble, and analyze the symbiotic relations between pictures and the meanings. In other words, phenomenon and essence, body and soul, feeling and reason, nature and culture, animal and human, etc., all these are not just a classification, but a generating mechanism, a representing mechanism.

In the double layer of narration, Malow's story has a lot of vagueness and blankness, intensifying the ambiguous meaning. This is why the novel was discussed about the theme once it published. For example, Kurtz's experiences are not fully developed; his fiancée expressed deep affection towards him, but their histories were not told; Malow's attitude toward him is ambiguous. In the binary opposition of many concepts, such as, black and white, decadence and redemption, disillusionment and hope, etc., were not ethnically chosen by the two narrators. Mixing with a bound of ambiguous pictures, the indecisive meaning is fluid and uncatchable.

After Kurtz's death, Marlow has a description of his feeling, "droll thing life is - that mysterious arrangement of merciless logic for a futile purpose. The most you can hope from it is some knowledge of yourself - that comes too late - a crop of the most unexciting contest you can imagine. It takes place in an impalpable greyness, with nothing 
underfoot, with nothing around, without spectators, without nothing underfoot, with nothing around, without spectators, without glamour, without glory, without the great desire of victory, without the great fear of defeat, in a sickly atmosphere of tepid skepticism, without much belief in your own right, and still less in that of your adversary."[4] From this picture, the readers feel a sudden breakdown of some intense emotions. It is not a hero's death fulling with integrity and dignity as Aristotle defined what the tragic is. Conrad intentionally damaged a traditional tragic to use a cracked portraying, which readers cannot feel indebted as if it were received in person. The fragmentation and debris of the pictures is a better artistic manner in describing death than wholeness and integrity. And this is coincidence with what Benjamin's allegory, not a skill of metaphor, but a way of expression, a meaning generating mechanism.

The images presented by Conrad's exquisite description can be seen everywhere, from strange calm to devastation. The reading dilemma caused by fracture constantly tears the feelings brought by image narration, and the description of realistic scene constantly jumps, is shelved and forgotten. The biggest challenge of this novel to readers is the tension brought by the authenticity and discontinuity of the image. Finally, the reader will fall into Benjamin's "melancholy meditation", [5] whose essence is to eliminate the last illusion of the real world and open our repeated viewing of the dark world. Conrad uses the allegorical mechanism to decompose the theme we understand each time into fragments. Therefore, the discussion on whether the theme of the heart of darkness is colonialism or anti colonialism, criticism of evil or praise of imperialism has been long and unresolved.

Conrad's exquisite portraying with broken pictures is all over the novel. He is trying to lead an allegory way of viewing. Readers attempt to remember the details but always fail because of the fracture, which formed a reading dilemma to constantly challenge the readers' feelings. The allegory tore our understanding into pieces and at last we should clean up the illusions and get start reading from the beginning all over again. Because of this, the discussions on the theme of the novel whether it's imperialism or anti-imperialism, it's curse for the evil or praise for the empire, is discussing and fighting on and on without any final conclusion. The continuous debate has accomplished the novel to the greatest one in the English literature.

\section{CONCLUSION}

In the western culture, the word see frequently equals to the word understand, which can be explained that vision has the function of recognition. In the Pictorial Turn, W.J.T. Michael pointed out that visional culture have implied the turn of thinking paradigms. [6] Ekphrasis is not only a relation between picture and language, but a complex interaction among ideology, social system, power, and identity. Foucault thought there are infinite nexus of words and things, so does the relation between the pictures and the language. We should analyze and grasp it in the concrete context.

What Conrad emphasis is the psychological experience by ekphrasis, which is the description and the question of the modernity, darkness and death. The juxtaposition, and the collage of the picture as well as the scattered perspectives challenges the traditional way of seeing and further doubts the historical authority. The allegorical expression is not a single layer structure established by author, but multi-layers springing from different language levels. And the meaning of the novel is continuous generating. Hence, the Heart of Darkness continues to disassemble and construct an artistic reality that comes from itself and resists itself. It always points to "another kind of speech", and the meaning of its fracture and blank is more continuous

\section{AUTHORS' CONTRIBUTIONS}

This paper is independently completed by Fan Chen.

\section{REFERENCES}

[1] Perry Meisel. Decentering "Heart of Darkness" [J]. Modern Language Studies.1978 (8): 20-28.

[2] Vincent Pecora. Heart of Darkness and the Phenomenology of Vocie [J]. ELH.1985 (52): 993-1015.

[3] F.R. Leavis. The Great Traditions [M]. Beijing: SDX Joint Publishing Company. 2002.

[4] Conrad. Heart of Darkness [M]. Beijing: The Commercial Press. 2019

[5] R. Jakobson. Selected Writings, IV [M]. The Haque-Paris. 1966.

[6] W.J.T Mitchell. Picture Theory [M]. Chicago: The University of Chicago Press. 1995. 